\title{
Pancreatic Intraductal Papillary Mucinous Neoplasm, Oncocytic-Type
}

National Cancer Institute

\section{Source}

National Cancer Institute. Pancreatic Intraductal Papillary Mucinous Neoplasm,

Oncocytic-Type. NCI Thesaurus. Code C95514.

A pancreatic intraductal papillary mucinous neoplasm characterized by the presence of neoplastic epithelial cells with abundant eosinophilic granular cytoplasm. 